\title{
The relationship between exercise intensity and performance in drills aimed at improving the proficiency, technical and tactical skills of basketball players.
}

\section{Relación entre el rendimiento de la capacidad de decisión y la intensidad de ejercicios de asimilación táctica en baloncesto.}

\author{
Ignacio Refoyo Roman \\ Javier Sampedro Molinuevo \\ Manuel Sillero Quintana \\ Facultad de Ciencias de la Actividad Física y del Deporte. INEF \\ Universidad Politécnica de Madrid
}

\begin{abstract}
Training programs for basketball players are often targeted at improving game tactics. The main objectives of this study were: a) to establish a relationship between exercise intensity and performance in basketball technical and tactical proficiency drills; and b) to determine the existing relationship between the opposition exerted by a direct opponent and the exercise intensity needed for the attacker to overcome this opposition. The study participants were 11 basketball players aged 17-18 years who had reached the top level in their age category. The players first underwent an incremental exercise test to establish heart rates corresponding to the ventilatory thresholds VT1 and VT2 as a measure of exercise intensity. Next, they performed a set of game-related technical/tactical exercises in conditions of defensive numerical equality or superiority. In these tests, physiological variables were recorded in contingency tables along with measures of the players' technical prowess and tactical decision capacity both as qualitative scores and quantitative variables. Our findings indicate that subjects in more physically demanding situations made more incorrect tactical decisions. Also, in conditions of greater opposition by the defence player, the attacker showed a worse tactical decision score and had to make a greater physical effort to overcome this opposition.
\end{abstract}

Key words: basketball; performance; decision-making; technical skills; tactics; exercise intensity.

\section{Resumen}

Los principales objetivos de este estudio han sido: a) establecer una relación entre intensidad y rendimiento en ejercicios de asimilación técnica y táctica en baloncesto, y b) determinar la relación existente entre la oposición de un contrario directo e intensidad del atacante para superarlo. Para la realización de dicho estudio se ha contando con 11 jugadores, de 17-18 años de edad y de máximo nivel en su categoría. Las pruebas realizadas a los sujetos comprendieron una prueba de esfuerzo y pruebas de campo, consistentes en la realización de ejercicios técnico-tácticos de igualdad y superioridad numérica ofensiva, donde se registraron los parámetros fisiológicos necesarios para llevar a cabo el estudio, además de la capacidad de decisión táctica y técnica de los jugadores, tomando como modelo una tabla de registro donde se anotaron, sobre escalas ordinales o cualitativas, aspectos relacionados con los siguientes puntos: aspectos individuales y aspectos de la acción de juego.

Los resultados manifiestan que sujetos que se encuentran en situaciones de elevada intensidad realizarán un mayor número de decisiones tácticas incorrectas. Además atendemos a que durante una mayor oposición por parte del contrario, mayor equivocación en la toma de decisión del atacante, además de una mayor exigencia física para superarlo.

Palabras clave: baloncesto; rendimiento; toma de decisión; habilidades técnicas; táctica; intensidad del ejercicio. 
Refoyo, I.; Sampedro, J.; Sillero, M. (2009). The relationship between exercise intensity and performance in drills aimed at improving the proficiency, technical and tactical skills of basketball players. Revista Internacional de Ciencias del Deporte. 14(5), 1-10. http://www.cafyd.com/REVISTA/01401.pdf

\section{Introduction}

major concern of the professionals responsible for high sports performance in basketball is the design of optimal training programs that will lead to better decision making during play, thus improving game tactics. Clearly, such training programs should consider the optimal workload characteristic to this particular sports activity in terms of intensity and duration and should also incorporate game manoeuvres specific to basketball. Moreover, these game-related drills also need to be performed at an appropriate exercise intensity to allow for the assessment of a player's tactical prowess.

This study was designed to establish the relationship between exercise intensity and performance in drills aimed at improving the technical and tactical skills of basketball players. As a secondary goal, we tried to determine the relationship between the opposition manifested by the direct defender and the exercise intensity of the attacker required to overcome this opposition.

\section{Materials and methods}

\section{Subjects}

The study subjects were 11 basketball players aged 17-18 years who were top-level players in their age category in Spain. All the subjects gave their written informed consent to participate after the study protocol and aims had been explained to them.

\section{Ergospirometry and exercise tests}

Expired air composition and volume were determined using an instrument set up (Medical Graphics Corporation, CPX, St Paul, USA) that includes an analyzer comprised of a zirconium cell to measure oxygen concentrations and infrared rays for carbon dioxide determination. The expiratory volume is estimated by a pneumotacograph. The analyzer and pneumotacograph were calibrated before each test. The analyzer was linked to a computer for all data processing. The software used, analyses the data to provide means for 8 respiratory movements or for a defined period of time, and will also transform the data to STPD (standard conditions of temperature and pressure - dry), ATPS (ambient temperature and pressure saturated with water vapour) and/or BTPS (body temperature and pressure saturated with water vapour).

Incremental endurance exercise tests were performed on a treadmill (Power Jog, Cardiokinetics Ltd, Salford, UK) with a $171 \mathrm{x} 53 \mathrm{~cm}$ running surface and a precision of \pm 0.2 $\mathrm{km} \cdot \mathrm{h}$. The protocol involved a 7 minutes warm up at $5 \mathrm{~km} \cdot \mathrm{h}$, a 5 minutes recovery period and an incremental exercise test at a constant $3 \%$ inclination in which the velocity was increased by $1 \mathrm{~km} \cdot \mathrm{h}$ every $2 \mathrm{~km}$ starting from the warm up velocity.

\section{Video recordings}

Game actions were recorded using two analog video cameras: a Panasonic VHS and Sony Hi 8. Recorded images were transferred to a PC (Pentium IV/550 mHz) with a 64 Mbyte graphics card by "Avermedia TV Capture”. Images were processed using Adobe Premier 5.0 software. 
Refoyo, I.; Sampedro, J.; Sillero, M. (2009). The relationship between exercise intensity and performance in drills aimed at improving the proficiency, technical and tactical skills of basketball players. Revista Internacional de Ciencias del Deporte. 14(5), 1-10. http://www.cafyd.com/REVISTA/01401.pdf

Using the video editing program, images were stored with a precision of 15 photograms per second in VCD format. During the editing process, a chronometer was added to the images such that timing started when the players made a gesture (lowered their arm) to indicate the start of HR monitoring.

\section{Field tests}

Heart rates in the game-related exercise tests were recorded every $5 \mathrm{~s}$ using a Polar Acurex Plus/Polar Interface Plus (Polar Electro Oy, Kempele, Finland) telemetric system including Training Advisor software for Windows (Polar Electro Oy, Kempele, Finland). This system has been previously validated (Leger and Thiviege, 1988; Ali and Farraly, 1991; Gretebeck et al., 1991).

To assess the players' technical and tactical skills, specific game actions were selected from those recommended in the literature specified in basketball training to evaluate real game situations. These manoeuvres or drills were classified into those of defensive numerical equality or superiority. Within the former, the two basic situations tested were 1 against 1 and 2 against 2, and for the latter they were 2 against 1 and 3 against 2. The final selection of these exercises was validated by 17 experts (national league coaches and national selectors of different categories).

To ensure the players required a wide range of exercise intensities to complete the game drills, each exercise was performed at three intensity levels. Thus each player took $15 \mathrm{~min}$ to complete each test at the three exercise intensities of $5 \mathrm{~min}$ each. The intensity of exercise was increased by reducing the resting interval between stages of attack or defence or by increasing the distance at which the stages were performed (e.g. by including a $20 \mathrm{~m}$ sprint between stages). The three actual levels of exercise intensity were measured during the tests in terms of the heart rate corresponding to $<\mathrm{VT} 1$, between VT1 and VT2, and >VT2 and defined respectively as low, intermediate and high.

Tactical decision capacity and technical proficiency were assessed when the players were in possession of the ball, that is, only the manoeuvres performed by the attacker. Decisionmaking and drill completion were graded by a non-participating observer who recorded the following qualitative and quantitative data in contingency tables:

Individual factors: player, position played anthropometric variables and physiological thresholds.

Game-related factors: type of drill, intensity level, tactical decision score, technical proficiency score, level of opposition exerted by the defence player (graded as low, intermediate or high) and heart rate during drill execution.

When assessing game-related drills, the general criteria of the observation method were considered, which Moreno and Pino (2000) describe as a guarantee of measuring what we observe. Using this method, we can be sure that several observers, in our case three, will equally evaluate the decisions made by the players.

These criteria first of all include considering the reliability of observation. This reliability can be viewed from a temporal standpoint (temporal reliability), which contemplates the reliability of a test performed on at least two temporally separated occasions. In the present study, three observations were made by each observer/expert: an initial observation of continuous drills in which no data were recorded; a second observation in which the data defined above were recorded; and a third one in which the same data were recorded. To 
Refoyo, I.; Sampedro, J.; Sillero, M. (2009). The relationship between exercise intensity and performance in drills aimed at improving the proficiency, technical and tactical skills of basketball players. Revista Internacional de Ciencias del Deporte. 14(5), 1-10. http://www.cafyd.com/REVISTA/01401.pdf

establish the reliability of these last two sets of measures, approximately 300 data (some $10 \%$ of all the data recorded) recorded by each observer during each observation (second and third) were found to show a correlation coefficient of 0.90 , such that the method was considered sufficiently reliable.

A second prerequisite is inter-observer reliability. To ensure this type of reliability, the triangular procedure was used and three observers appointed. For the 300 data recorded, the correlation coefficient among the three observers was 0.92, thus establishing the second reliability criterion. Before the observation procedure, the three observers underwent a training period according to the procedures and conditions proposed by Anguera (1983).

\section{Experimental design}

1. Ventilatory maxima and thresholds were determined in the incremental exercise test. Running speeds were also recorded.

2. A week later, the game-relate exercises were performed as follows: on Monday and Wednesday the numerical equivalence drills and on Thursday and Friday, the numerical superiority drills. During the tests, heart rates were monitored and images for each situation recorded.

These two sets of tests were repeated after 18 weeks and referred to as tests 1 and 2. During this period, the training volume and competitions performed by the players were recorded as the number of sessions per player. In total, the players underwent 55 technical/tactical drill sessions, 49 physical training sessions, 28 days of rest, 22 competition matches and 8 friendly matches.

The Chi-squared test $\left(\chi^{2}\right)$ was used for statistical comparisons. The reliability of the measures and procedures was assessed by estimating Pearson correlation coefficients. All statistical tests were performed using SPSS software.

\section{Results}

\section{Tactical decision-making and exercise intensity}

First, we estimated the proportions of incorrect decisions and drills executed in relation to the correct ones. The overall percentages obtained for the correct and incorrect decisions (for test 1 plus test 2$)$ differed significantly $(P<0.001)$ according to the exercise intensity level, as determined by the heart rate (Table 1 ).

Tabla 1.Contingency table tactical decision capacity and exercise intensity

\begin{tabular}{|c|l|c|c|c|c|}
\hline \multirow{2}{*}{ TACTICAL DECISIONS } & \multicolumn{3}{|c|}{ EXERCISE INTENSITY } & \multirow{2}{*}{ TOTAL } \\
\cline { 2 - 6 } & No. drills & 1450 & 1105 & 137 & 2692 \\
\hline \multirow{3}{*}{ CORRECT } & Expected no. drills & 1433.7 & 1098.6 & 159.8 & 2692 \\
\cline { 2 - 6 } & $\%$ INTENSITY & $\mathbf{8 7 . 3} \%$ & $\mathbf{8 6 . 9} \%$ & $\mathbf{7 4 . 1 \%}$ & $\mathbf{8 6 . 4 \%}$ \\
\cline { 2 - 6 } & $\%$ Total & $46.5 \%$ & $35.5 \%$ & $4.4 \%$ & $86.4 \%$ \\
\hline \multirow{3}{*}{ I NCORRECT } & No. drills & 210 & 167 & 78 & 425 \\
\cline { 2 - 6 } & Expected no. drills & 226.3 & 173.4 & 25.2 & 425 \\
\cline { 2 - 6 } & $\%$ INTENSITY & $\mathbf{1 2 . 7 \%}$ & $\mathbf{1 3 . 1 \%}$ & $\mathbf{2 5 . 9}$ & $\mathbf{1 3 . 6 \%}$ \\
\cline { 2 - 6 } & $\%$ Total & $6.7 \%$ & $5.4 \%$ & $1.5 \%$ & $13.6 \%$ \\
\hline \multirow{2}{*}{ TOTAL } & No. drills & 1660 & 1272 & 185 & 3117 \\
\cline { 2 - 6 } & $\%$ Total & $53.3 \%$ & $40.8 \%$ & $5.9 \%$ & $100 \%$ \\
\hline
\end{tabular}


Refoyo, I.; Sampedro, J.; Sillero, M. (2009). The relationship between exercise intensity and performance in drills aimed at improving the proficiency, technical and tactical skills of basketball players. Revista Internacional de Ciencias del Deporte. 14(5), 1-10. http://www.cafyd.com/REVISTA/01401.pdf

As may be observed in Table 1, out of a total number of 3117 decisions, $86.4 \%$ were correct and $13.6 \%$ were incorrect. The proportions of incorrect decisions were $12.7 \%$ for an exercise intensity level below VT1, 13.1\% for a level between VT1 and VT2, and 25.9\% for a level above VT2.

These findings indicate that when a higher physical effort is made by the player, the percentage of correct decisions in game-related exercises significantly diminishes.

\section{Technical proficiency and exercise intensity}

The percentages of drills correctly and incorrectly completed (test 1 plus test 2) differed significantly according to the exercise intensity level at a significance level of $P<0.002$ (Table 2).

Tabla 2. Contingency table drill execution and exercise intensity

\begin{tabular}{|c|c|c|c|c|c|}
\hline \multirow{2}{*}{\multicolumn{2}{|c|}{ DRILL EXECUTION }} & \multicolumn{3}{|c|}{ EXERCISE INTENSITY } & \multirow{2}{*}{ TOTAL } \\
\hline & & $\mathrm{HR}<\mathrm{VT} 1$ & HR VT1 - VT2 & HR $>$ VT2 & \\
\hline \multirow{4}{*}{ CORRECT } & No. drills & 1129 & 791 & 114 & 2034 \\
\hline & Expected no. drills & 1082.9 & 830,3 & 120,8 & 2034 \\
\hline & $\%$ INTENSITY & $68.1 \%$ & $62.2 \%$ & $61.6 \%$ & $65.3 \%$ \\
\hline & $\%$ Total & $36.2 \%$ & $25.4 \%$ & $3.7 \%$ & $65.3 \%$ \\
\hline \multirow{4}{*}{ I NCORRECT } & No. drills & 530 & 481 & 71 & 1082 \\
\hline & Expected no. drills & 576.1 & 441.7 & 64.2 & 1082 \\
\hline & $\%$ INTENSITY & $31.9 \%$ & $37.8 \%$ & $38.4 \%$ & $34.7 \%$ \\
\hline & \% Total & $17 \%$ & $15.4 \%$ & $2.3 \%$ & $34.7 \%$ \\
\hline \multirow{2}{*}{ TOTAL } & No. drills & 1659 & 1272 & 185 & 3116 \\
\hline & $\%$ Total & $53.2 \%$ & $40.8 \%$ & $5.9 \%$ & $100 \%$ \\
\hline
\end{tabular}

Before commenting on these results, it should be remembered that the factor drill completion was determined in relation to the efficiency of performance and not to a technical model.

As indicated in Table 2, 65.3\% of the game actions were executed correctly and $34.7 \%$ incorrectly. The percentages of incorrect actions by exercise intensity level were: $31.9 \%$ for a level below VT1, 37.8\% for a level between VT1 and VT2 and 38.4\% for an exercise intensity above VT2.

\section{Defence opposition and exercise intensity}

To relate technical-tactical aspects with physiological factors, we examined the relationship between the opposition exerted by the defence player, graded as being low, intermediate or high, and the heart rate values recorded in the attacker when faced with this opposition. These two factors were found to be significantly related at the level $P<0.05$ (Table 3). 
Refoyo, I.; Sampedro, J.; Sillero, M. (2009). The relationship between exercise intensity and performance in drills aimed at improving the proficiency, technical and tactical skills of basketball players. Revista Internacional de Ciencias del Deporte. 14(5), 1-10. http://www.cafyd.com/REVISTA/01401.pdf

Tabla 3. Contingency table defence opposition and exercise intensity

\begin{tabular}{|c|l|c|c|c|c|}
\hline \multicolumn{2}{|c|}{ DEFENCE OPPOSITION } & \multicolumn{3}{|c|}{ EXERCISE INTENSITY } & \multirow{2}{*}{ TOTAL } \\
\cline { 2 - 6 } & Ho. drills & 653 & 483 & 72 & 1208 \\
\hline \multirow{3}{*}{ LOW } & HRPected no. drills & 643.4 & 492.9 & 71.2 & 1208 \\
\cline { 2 - 6 } & \% OPPOSITION & $54.1 \%$ & $40 \%$ & $6 \%$ & $100 \%$ \\
\cline { 2 - 6 } & $\%$ Total & $21 \%$ & $15.5 \%$ & $2.3 \%$ & $38.8 \%$ \\
\hline \multirow{3}{*}{ INTERMEDI ATE } & No. drills & 738 & 541 & 70 & 1349 \\
\cline { 2 - 6 } & Expected no. drills & 718.5 & 550.4 & 80.1 & 1349 \\
\cline { 2 - 6 } & $\%$ OPPOSITION & $54.7 \%$ & $40.1 \%$ & $5.2 \%$ & $100 \%$ \\
\cline { 2 - 6 } & $\%$ Total & $23.7 \%$ & $17.4 \%$ & $2.2 \%$ & $43.3 \%$ \\
\hline \multirow{3}{*}{ HIGH } & No. drills & 268 & 247 & 43 & 558 \\
\cline { 2 - 6 } & Expected no. drills & 297.2 & 227.7 & 33.1 & 558 \\
\cline { 2 - 6 } & $\%$ OPPOSITION & $48 \%$ & $44.3 \%$ & $7.7 \%$ & $100 \%$ \\
\cline { 2 - 6 } & $\%$ Total & $8.6 \%$ & $7.9 \%$ & $1.4 \%$ & $17.9 \%$ \\
\hline \multirow{2}{*}{ TOTAL } & No. drills & 1659 & 1271 & 185 & 3115 \\
\cline { 2 - 6 } & $\%$ Total & $53.3 \%$ & $40.8 \%$ & $5.9 \%$ & $100 \%$ \\
\hline
\end{tabular}

Table 3 indicates that only $5.9 \%$ of the game play drills were undertaken at the higher exercise intensities, and although differences were not substantial, the higher the opposition exerted by the defence player, the higher the proportion of drills performed at the high intensity levels.

The percentage of drills completed at the highest intensity was $6 \%$ when opposition was low, $5.2 \%$ when intermediate and $7.7 \%$ when high.

These differences nevertheless increase if we consider the two higher intensity levels (VT1 to VT2 and above VT2) when the opposition manifested by the defence player was at its highest.

Tactical decision-making and opposition manifested

The decision capacity of the player was determined according to the opposition concept established previously. These two factors were also found to be significantly related at the level $P<0.001$.

According to the percentages recorded, as the opposition shown by the defender increased, the rate of incorrect tactical decisions made increased from $4.6 \%$ to $13.1 \%$ and then to $34.9 \%$ for situations of low, intermediate and high opposition, respectively.

\section{Tactical decision-making, opposition manifested and exercise intensity}

The opposition manifested by the defence player and the exercise intensity level were also found to affect the player's tactical decision capacity.

When the defence opposition was low, only $6 \%$ of the decisions were made at exercise intensity above the VT2, of which only $6.9 \%$ were incorrect.

In conditions of intermediate opposition, only $5.2 \%$ of the decisions were taken at an exercise intensity above the VT2, of which $27.1 \%$ were incorrect; at high opposition, $7.7 \%$ were taken above VT2, with 55.8\% incorrect decisions.

These observations indicate that with increasing opposition and physical demands, the tactical prowess of the subjects decreased. 
Refoyo, I.; Sampedro, J.; Sillero, M. (2009). The relationship between exercise intensity and performance in drills aimed at improving the proficiency, technical and tactical skills of basketball players. Revista Internacional de Ciencias del Deporte. 14(5), 1-10. http://www.cafyd.com/REVISTA/01401.pdf

\section{Changes in tactical decision capacity and exercise intensity over time}

When the results recorded during the course of the season were compared in terms of the decision capacity shown by the players, the results of test 2 were found to be improved over test 1 for each exercise intensity at the significance level $P<0.04$ (Table 4):

Tabla 4. Contingency table tactical decision capacity, test 1 vs. 2 and exercise intensity

\begin{tabular}{|c|c|c|c|c|c|}
\hline \multirow{2}{*}{\multicolumn{2}{|c|}{ TACTICAL DECISIONS TEST 1}} & \multicolumn{3}{|c|}{ EXERCI SE I NTENSITY } & \multirow{2}{*}{ TOTAL } \\
\hline & & $\mathrm{HR}<\mathrm{VT1}$ & HR VT1 - VT2 & $\mathrm{HR}>\mathrm{VT} 2$ & \\
\hline \multirow{4}{*}{ CORRECT } & No. drills & 733 & 589 & 99 & 1421 \\
\hline & Expected no. drills & 724.9 & 582.3 & 113.8 & 1421 \\
\hline & $\%$ INTENSITY & $83.4 \%$ & $83.4 \%$ & $71.7 \%$ & $82.5 \%$ \\
\hline & $\%$ Total & $42.5 \%$ & $34.2 \%$ & $5.7 \%$ & $82.5 \%$ \\
\hline \multirow{4}{*}{ INCORRECT } & No. drills & 146 & 117 & 39 & 302 \\
\hline & Expected no. drills & 154.1 & 123.7 & 24.2 & 302 \\
\hline & $\%$ INTENSITY & $16.6 \%$ & $16.6 \%$ & $28.3 \%$ & $17.5 \%$ \\
\hline & $\%$ Total & $8.5 \%$ & $6.8 \%$ & $2.3 \%$ & 17.5 \\
\hline \multirow{2}{*}{ TOTAL } & No. drills & 879 & 706 & 138 & 1723 \\
\hline & $\%$ Total & $51 \%$ & $41 \%$ & $8 \%$ & $100 \%$ \\
\hline \multirow{2}{*}{\multicolumn{2}{|c|}{ TACTICAL DECISIONS TEST 2}} & \multicolumn{3}{|c|}{ EXERCISE INTENSITY } & \multirow{2}{*}{ TOTAL } \\
\hline & & $\mathrm{HR}<\mathrm{VT1}$ & HR VT1 - VT2 & $\mathrm{HR}>\mathrm{VT} 2$ & \\
\hline \multirow{4}{*}{ CORRECT } & No. drills & 717 & 516 & 38 & 1271 \\
\hline & Expected no. drills & 712.1 & 516.1 & 42.9 & 1271 \\
\hline & $\%$ INTENSITY & $91.8 \%$ & $91.2 \%$ & $80.9 \%$ & $91.2 \%$ \\
\hline & \% Total & $51.4 \%$ & $37 \%$ & $2.7 \%$ & $91.2 \%$ \\
\hline \multirow{4}{*}{ I NCORRECT } & No. drills & 64 & 50 & 9 & 123 \\
\hline & Expected no. drills & 68.9 & 49.9 & 4.1 & 123 \\
\hline & $\%$ INTENSITY & $8.2 \%$ & $8.8 \%$ & $19.1 \%$ & $8.8 \%$ \\
\hline & $\%$ Total & $4.6 \%$ & $3.6 \%$ & $0.6 \%$ & $8.8 \%$ \\
\hline \multirow{2}{*}{ TOTAL } & No. drills & 781 & 566 & 47 & 1394 \\
\hline & $\%$ Total & $56 \%$ & $40.6 \%$ & $3.4 \%$ & $100 \%$ \\
\hline
\end{tabular}

It should be remembered that test 1 was performed at the start of the season and test 2 at the end. The rate of incorrect tactical decisions recorded in test $1(17.3 \%)$ was higher than in test 2 (8.8\%). Percentages by exercise intensity level for test 1 were: $16.6 \%(<\mathrm{VT} 1), 16.6 \%$ (VT1-VT2) and 28.3\% (>VT2). In the second test, the corresponding incorrect decision rates were lower, at $8.2 \%, 8.8 \%$ and $19.1 \%$, respectively.

Thus, both tests revealed that at exercise intensities above VT2, the percentage of incorrect decisions taken by the subjects increased significantly compared to the lower exercise intensities.

Finally, no significant differences emerged when we analysed possible relations among the percentages of correctly completed drills, the results of tests 1 and 2 and the exercise intensity levels. 
Refoyo, I.; Sampedro, J.; Sillero, M. (2009). The relationship between exercise intensity and performance in drills aimed at improving the proficiency, technical and tactical skills of basketball players. Revista Internacional de Ciencias del Deporte. 14(5), 1-10. http://www.cafyd.com/REVISTA/01401.pdf

\section{Discussion}

Our findings reveal a significant relationship between tactical decision-making in gamerelated field exercises and the ventilatory thresholds of the basketball players determined in the laboratory. The high overall rate of correct tactical decisions made in the two tests conducted (86.4\%) reflects the high tactical proficiency of our study population of top-level players.

A further significant finding was the low number of tactical decisions (5.9\%) recorded at exercise intensities exceeding the VT2. This could be explained by the higher heart rates and blood lactate concentrations observed during competition as opposed to training by Rodríguez et al (1997) and Tessitore et al. (2006), since our game-related exercises were performed in training conditions.

In our analysis of completed game play drills and the exercise intensity level, a scarce difference was observed between the higher intensity levels (37.8\% incorrectly completed at the VT1-VT2 transition versus $38.4 \%$ above VT2), and only a small difference was noted between these higher intensity levels and the lower level (31.9\% incorrectly completed drills below the VT1). Similarly, few manoeuvres were completed at an exercise intensity above VT2 (5.9\%) confirming the above finding.

When we examined tactical decision-making in terms of the opposition experienced by the player, it was noted that during training, fewer drills were completed in a situation of high defence opposition than in conditions of less opposition. Notwithstanding, it was observed that the number and percentage of incorrect decisions increased as the level of opposition rose. Like physical demand increases, the demand also increases cognitive (Helsen et al. 2004). These observations may be related to different exercise intensity during competition and training, meaning that during a match the player is faced with greater defence opposition requiring greater physical exertion to overcome this opposition. We must also include the psychological impact of various actions of opposition both in training and, especially in competition that may affect the value of heart rate. (Martinmaki et al. 2006).

Terrados et al. (1995) reported that heart rates measured in a female basketball team taking part in international competitions were higher $(185.7 \pm 3.5 \mathrm{bpm})$ than heart rates recorded in a matched female team that only played national matches $(174.6 \pm 12.9 \mathrm{bpm})$. In this same line, Riezebos et al. (1983) finds great importance in the anaerobic metabolism of sport performance for basketball female players.

Ali and Farrally (1991), Rampinini et al. (2004), Mohr et al. (2004), Kasilkcoioglu, et al. (2004), Arosos et al.(2004) and Shirreffs et al (2005) shows similar data in other team sports like soccer.

These data suggest that the higher the technical-tactical demands, the higher the physical effort needed to overcome these demands. Thus, since our study was performed in training conditions, the physical exertion required was probably lower, among other reasons, because of the lower degree of opposition the attacker has to deal with.

The results obtained for tactical decision-making and defender opposition in terms of the exercise intensity. These findings indicate the lack of a linear relationship between these factors and exercise intensity, although we did note that the percentage of decisions taken at the highest intensity level was higher when there was greater defence opposition, being $6.0 \%$ in conditions of low opposition, 5.2\% for intermediate levels and $7.7 \%$ for the high opposition 
Refoyo, I.; Sampedro, J.; Sillero, M. (2009). The relationship between exercise intensity and performance in drills aimed at improving the proficiency, technical and tactical skills of basketball players. Revista Internacional de Ciencias del Deporte. 14(5), 1-10. http://www.cafyd.com/REVISTA/01401.pdf

level. However, the most significant finding was that at the highest exercise intensity, that is, above VT2, the number of incorrect decisions made was much higher when defence opposition was high, the rate recorded being 55.8\%. For this highest exercise intensity level, the proportion of incorrect decisions made when confronted with intermediate opposition was $27.1 \%$, while the rate recorded for the lowest level of opposition was only $6.9 \%$. Thus, there seems to be some sort of relationship between the percentage of incorrect decisions and the degree of defender opposition. Similarly, we found that greater opposition poses higher physiological demands on the player in possession of the ball.

Finally, we examined the changes experienced by the different variables analysed during the two sets of tests performed at the start and end of the basketball season. As mentioned above, during the course of training several variables will contribute to the better or worse performance of a player. The variables selected for our study were those that can be assessed fairly objectively such as the drills and technical/tactical skills used in training and competition sessions and the training volume. However, we are aware there are many subjective variables (physiological, psychological, social factors etc.), which are difficult to assess or quantify, that could also markedly influence the performance of a player during the training process.

Despite this limitation, we were able to observe that the rate of correct decisions made in the second test was improved by $8.5 \%$ over the first test. However, when we tried to relate the percentage of correct decisions and exercise intensity in the two tests, it emerged that less decisions were taken at the higher exercise intensities in the second test (3.4\%) than the first (8\%). This could suggest that the players become adapted to the specific demands of the game and avoid reaching exercise intensities of high fatigue, that is, situations that surpass the second ventilatory threshold.

Besides this decrease in the number of decisions made, we found that the proportion of incorrect decisions recorded for this highest exercise intensity level was lower in the second than the first test. Hence, we could say that less decisions (fewer were made at the higher exercise intensities in the second test but that more of these decisions were correct). This trend was also noted across the lower exercise intensity levels.

\section{Conclusions}

In summary, our findings indicate that: (a) when a basketball player is subjected to a situation of intense physical demand, more incorrect tactical decisions are made than in less demanding situations; (b) no differences in performance are observed at intermediate and high exercise intensities and the difference between performance at these and a low intensity level is scarce; (c) the higher the opposition manifested by the defender, the greater the number of incorrect tactical decisions made by the attacker; and (d) during the course of training, tactical decisionmaking in game-related drills improves regardless of the exercise intensity. 
Refoyo, I.; Sampedro, J.; Sillero, M. (2009). The relationship between exercise intensity and performance in drills aimed at improving the proficiency, technical and tactical skills of basketball players. Revista Internacional de Ciencias del Deporte. 14(5), 1-10. http://www.cafyd.com/REVISTA/01401.pdf

\section{References}

Ali A, Farrally, M (1991). Recording soccer players' heart rates during matches. J ournal of Sports Sciences 9, 183-189.

Anguera, T. (1983). Manual práctico de observación. Trillas. Méjico.

Arosos, J.; Rebelo, A.N.; Gomes-Pereira, J. (2004). Physiological impact of selected game-related exercises. Journal of Sports Sciences, 22(6), 522.

Gretebeck, R.J.; Montoye, H.; Bailor, D.; Montoye, A.P. (1991). Comment on heart rate recording fields studies. J ournal of Sport Medical Physical Fitness, 31, 629-631.

Helsen, W.; Bultynck, J.B.; Weston, M. (2004). Physical and cognitive demands of topclass football refereeing. Journal of Sports Sciences, 22(6), 545-546.

Kasilkcoioglu, E.; Kayserilioglu, A.; Yildiz, S.; Akhan, H.; Cuhadaroglu, C. (2004). Qt Dispersion in Soccer Players During Exercise Testing. International J ournal of Sports Medicine, 25(3), 177-181.

Leger, L.; Thiviege, M. (1988). Heart rate monitors: validity, stability, and functionality. The Physician and Sportmedicine, 5, 143-151.

Martinmaki, K.; Rusko, H.; Kooistra, L.; Kettunen, J. \& Saalasti, S. (2006). Intraindividual validation of heart rate variability indexes to measure vagal effects on hearts. American Journal of Physiology- Heart and Circulatory Physiology, 290(2), 640-647.

Mohr, M.; Ellingsgaard, H.; Andersson, H.; Bangsbo, J.; Krustrup, P. (2004) Physical demands in high-level female soccer: Application of fitness tests to evaluate match performance. Journal of Sports Sciences, 22(6), 552-553.

Rampinini, E.; Sassi, A.; Impellizzeri, F.M. (2004). Reliability of heart rate recorded during soccer training. J ournal of Sports Sciences, 22(6), 558-559.

Riezebos, M.L.; Paterson, D.H.; Hall, C.R.; Yuhasz, M.S. (1983). Relationship of selected variables to performance in women's basketball. Canadian Journal of Applied Sport Sciences. 8, 34-40.

Rodríguez, M.; Terrados, N.; Pérez-Landaluce, J.; Fernández, B.; García-Herrero, F. (1998). Déficit máximo acumulado de oxígeno en baloncesto femenino. Archivos de Medicina del Deporte, Vol. XV, 64, 115-122.

Shirreffs, S.M.; Aragon-Vargas, L.F.; Chamorro, M.; Maughan, R.J.; Serratosa, L.; Zachwieja, J.J. (2005). The Sweating Response of Elite Professional Soccer Players to Training in the Heat. International J ournal of Sports Medicine, 26(2), 90-95.

Terrados, N.; Fernández, B.; Pérez-Landauce, J.; Rodríguez, M.; Coloma, M.; Buceta, J.M. (1995). Physiological aspects of women's basketball. Medicine and Science in Sport and Exercise, S24, 142.

Tessitore, A.; Tiberi, M.; Cortis, C.; Rapisarda, E.; Meeusen, R. \& Capranica, L. (2006). Aerobic-anaerobic profiles, heart rate and match analysis in old basketball players. Gerontology, 52(4), 214-222. 